\title{
Identification of common predictors of surgical outcomes for epilepsy surgery
}

\author{
This article was published in the following Dove Press journal: \\ Neuropsychiatric Disease and Treatment \\ 5 November 2013 \\ Number of times this article has been viewed
}

\section{Jing Zhang' \\ Weifang Liu' \\ Hui Chen' \\ Hong Xia' \\ Zhen Zhou' \\ Shanshan $\mathrm{Mei}^{2}$ \\ Qingzhu Liư \\ Yunlin $\mathrm{Li}^{2}$}

'School of Biomedical Engineering, Capital Medical University,

${ }^{2}$ Department of Functional

Neurology and Neurosurgery,

Beijing Haidian Hospital, Beijing,

People's Republic of China
Correspondence: Jing Zhang

School of Biomedical Engineering,

Capital Medical University, Number 10

Xitoutiao, You An Men St,

Beijing 100069, People's

Republic of China

Tel +86 I0 839| I543

Fax +86 I0 839I I544

Email jzhang0000@163.com

\begin{abstract}
Although epilepsy surgery is an effective treatment for patients with drug-resistant epilepsy, surgical outcomes vary across patient groups and studies. Identification of reliable prognostic factors for surgical outcome is important for outcome research. In this study, recent systematic reviews and meta-analyses on prediction of seizure outcome have been analyzed, and common predictors of seizure outcome or unrelated factors for temporal lobe epilepsy (TLE), lesional extratemporal lobe epilepsy (ETLE), and tuberous sclerosis complex have been identified. Clinical factors such as lesional epilepsy, abnormal magnetic resonance imaging, partial seizures, and complete resection were found to be common positive predictors, and factors such as nonlesional epilepsy, poorly defined and localized epileptic focus, generalized seizures, and incomplete resection are common negative predictors, while factors such as age at surgery and side of surgery are unrelated to seizure outcome for TLE and lesional ETLE. In addition, diagnostic neuroimaging and resection are among the most important predictors of seizure outcome. However, common predictors of seizure outcome could not be identified in nonlesional ETLE because no predictors were found to be significant in adult patients (by meta-analysis), and outcome prediction is difficult in this case. Meta-analysis of other outcomes, such as neuropsychologic outcomes, is rare due to lack of evaluation standards. Further studies on identification of reliable predictors of surgical outcomes are needed.
\end{abstract}

Keywords: neuroimaging, epilepsy surgery, outcome prediction, common predictors

\section{Introduction}

Around one third of patients with focal seizures are resistant to antiepileptic drugs. For these patients, epilepsy surgery brings the hope of a seizure-free outcome and improved quality of life. Epilepsy surgery can achieve a 60\%-90\% likelihood of seizure-free outcome in patients with temporal lobe epilepsy (TLE) and 40\%-60\% in extratemporal lobe epilepsy (ETLE). ${ }^{1}$ However, there are still uncertainties in surgical candidates, and it is important to estimate possible risks, identify factors related or unrelated to outcomes, and predict postoperative outcomes prior to surgery.

The predictive value of neuroimaging for epilepsy surgical outcome has been reported by a number of studies. For example, Lerner et al, ${ }^{2}$ Cossu et al, ${ }^{3}$ Widdess-Walsh et al, ${ }^{4}$ and Jeha et $\mathrm{al}^{5}$ have shown that complete resection of the abnormality detected by preoperative magnetic resonance imaging (MRI) is the most important predictor of a favorable postoperative outcome. Functional neuroimaging modalities, such as magnetoencephalography (MEG)/ magnetic source imaging (MSI), positron emission tomography (PET), and ictal singlephoton emission computed tomography (SPECT) also have clinical value in predicting seizure-free outcome. ${ }^{6}$ In addition, Kuzniecky et al, ${ }^{7}$ Eberhardt et al, ${ }^{8}$ and Stefan et $\mathrm{al}^{9}$ have 
demonstrated that bilateral magnetic resonance spectroscopy (MRS) metabolite alterations in TLE with hippocampal sclerosis (HS) have a predictive value for surgical outcome.

In addition to neuroimaging, other predictors and risk factors for seizure outcome have also been identified. The presence of radiographic mesial temporal sclerosis (MTS) is considered to be a factor predictive of a favorable seizure outcome after surgical intervention. ${ }^{10}$ The surgical option of localized frontal resection versus more extensive lobectomy with/without an extrafrontal component has been found to be predictive of outcome after frontal lobectomy, ${ }^{11}$ while bilateral temporal onset, ${ }^{12}$ frequent secondary generalized seizures, ${ }^{13,14}$ and head trauma ${ }^{15}$ have been identified as poor predictors of seizure control.

In general, reasons for failure of epilepsy surgery are multifactorial, ${ }^{16,17}$ and outcome predictors are hard to identify, especially in nonlesional TLE or ETLE cases. ${ }^{18-20}$ On the other hand, patients with unilateral radiographic mesial temporal sclerosis are considered to be the "ideal" candidates for epilepsy surgery. Recently, Feis et $\mathrm{al}^{21}$ studied patients with left TLE ( $n=49,89.8 \%$ or 44/49 with hippocampal sclerosis) who underwent selective amygdalohippocampectomy, and found that surgical outcome could be predicted in males $(94 \%$ balanced accuracy) and in females ( $96 \%$ balanced accuracy) using presurgical structural MRI.

However, the above study findings triggered the following questions. How applicable is such high-accuracy outcome prediction? In addition to predicting outcome in unilateral lesional TLE, what about outcome prediction in bilateral TLE, nonlesional TLE, or ETLE cases? What is the full and real picture of surgical outcome prediction? Is seizure outcome in general predictable? How are the presurgical findings related to surgical outcomes? Is it possible to use presurgical neuroimaging and/or other factors to predict surgical outcomes? How reliable are the predictors? Since the findings vary among studies, is it possible to identify common predictors based on the findings of systematic reviews and meta-analyses? Further, what is the role of presurgical neuroimaging in predicting seizure outcome? Moreover, in addition to seizure outcome, how good is the prediction of other outcomes? To address the above questions, recent systematic reviews and meta-analyses on epilepsy surgical outcome prediction were reviewed and their findings were analyzed.

\section{Methods}

\section{Paper selection and classification}

A Medline query was performed via PubMed using the keywords "epilepsy", "surgical outcome", and "predictor" for papers published since 2000 . The articles were filtered for reviews and meta-analyses. Ten meta-analyses and three comprehensive reviews on seizure outcome prediction were indentified. The articles were classified according to epilepsy substrates as lesional or nonlesional TLE, ETLE, or tuberous sclerosis complex (TSC). In addition, to understand predictors of other outcomes and the role of other factors (such as type of surgery), further Medline queries were undertaken. Four related articles (two reviews and two meta-analyses) on other outcomes and four metaanalyses on surgical options or other interventions were identified.

Table 1 gives an overview of the literature studied in this paper. The literature was classified as lesional or nonlesional TLE or ETLE subgroups. Lesion in this paper refers to mesial temporal sclerosis or hippocampal sclerosis, gliotic tissue, tumors, and other circumscribed anomalies, including malformations of cortical development and focal cortical dysplasia. ${ }^{22}$ In addition, tubers in tuberous sclerosis complex were considered to be special lesions, and meta-analyses on outcome prediction in tuberous sclerosis complex were classified as a separate subgroup. Further, given that the majority of epilepsy cases in Tonini et $\mathrm{al}^{23}$ and Téllez-Zenteno et $\mathrm{al}^{1}$ were TLE, these two articles were counted as those addressing seizure outcome in TLE. Moreover, since the majority of epilepsy cases in TéllezZenteno et $\mathrm{al}^{22}$ were lesional, this paper was classified into lesional epilepsy subgroups.

\section{Extraction of findings}

To summarize the findings of the meta-analyses and reviews, outcome predictors (both positive and negative) and unrelated factors were extracted from the results of the papers. To overcome the variations between studies, common predictors of seizure outcome were extracted from the findings of the meta-analyses and reviews.

Common predictors or factors unrelated to surgical outcome in the literature were identified by counting the frequency of appearance of a predictor/unrelated factor in every literature subgroup (such as lesional or nonlesional TLE). If the papers in a literature subgroup had overlap (eg, for adults with lesional TLE), and the frequency of a predictor/unrelated factor was $\geq 2$, the predictor/unrelated factor was considered to be as a common predictor/unrelated factor. On the other hand, if the papers in a literature subgroup had no overlap (eg, one for children and the other for adult patients), then the predictors/factors found by meta-analysis were still considered. 
Table I Overview of literature on predictors of seizure outcome after surgery for epilepsy

\begin{tabular}{|c|c|c|}
\hline & TLE & ETLE \\
\hline \multirow[t]{7}{*}{ Lesional } & Mclntosh et al (review) ${ }^{41}$ & Téllez-Zenteno et $\mathrm{a}^{22}$ \\
\hline & Tonini et $\mathrm{al}^{23}$ & Rowland et al ${ }^{26}$ (FCD) \\
\hline & Téllez-Zenteno et al' & Englot et al" (FLE) \\
\hline & Téllez-Zenteno et $\mathrm{a}^{22}$ & Englot et al ${ }^{43}$ (children) \\
\hline & Rowland et al ${ }^{26}$ (FCD) & \\
\hline & Englot et $\mathrm{al}^{42}$ (children) & \\
\hline & Najm et al ${ }^{25}$ (review) & \\
\hline \multirow[t]{7}{*}{ Nonlesional } & Mclntosh et al (review) ${ }^{41}$ & Ansari et $\mathrm{al}^{20,44}$ (adults \\
\hline & Tonini et $\mathrm{a}^{23}$ & and children) \\
\hline & Téllez-Zenteno et al' & Englot et al" (FLE) \\
\hline & Téllez-Zenteno et $\mathrm{a}^{22}$ & Englot et al ${ }^{43}$ (children) \\
\hline & Rowland et al ${ }^{26}$ (FCD) & \\
\hline & Englot et $\mathrm{al}^{42}$ (children) & \\
\hline & Najm et al ${ }^{25}$ (review) & \\
\hline \multirow[t]{3}{*}{ TSC } & Jansen et $\mathrm{al}^{27}$ (review) & \\
\hline & Zhang et $\mathrm{al}^{45}$ & \\
\hline & Fallah et $\mathrm{a}^{46}$ & \\
\hline
\end{tabular}

\begin{tabular}{ll}
\hline Other outcomes & $\begin{array}{l}\text { Surgical options and } \\
\text { other interventions }\end{array}$ \\
\hline $\mathrm{Vaz}^{35}$ & Spencer et al ${ }^{39}$ \\
${\text { Schmidt et a }{ }^{32} \text { (review) }}_{\text {Téllez-Zenteno et al }}^{33}$ & Schmidt and Stavem \\
Ives-Deliperi and Butler $^{37}$ (review) & Englot et al ${ }^{40}$ \\
\hline
\end{tabular}

Note: Papers marked as review are review papers, otherwise are meta-analyses. Abbreviations: FLE, frontal lobe epilepsy; FCD, focal cortical dysplasia; ETLE, extratemporal lobe epilepsy; TLE, temporal lobe epilepsy; TSC, tuberous sclerosis complex.

\section{Results}

\section{Prediction of seizure outcome}

The outcome predictors and factors unrelated to seizure outcome in patients with lesional or nonlesional TLE extracted from the literature are listed in Table 2. For patients with lesional or nonlesional ETLE, predictors and unrelated factors are listed in Table 3 (lesional ETLE) and Table 4 (nonlesional ETLE). Predictors and unrelated factors in patients with tuberous sclerosis complex are shown in Table 5.

The predictors and factors unrelated to seizure outcome identified by the reviews and meta-analyses varied between patient groups and studies. In patients who underwent temporal lobectomy, seizure outcome was associated with a number of predictors, including diagnostic neuroimaging, lesional versus nonlesional epilepsy, and complete versus incomplete resection. However, in challenging epilepsy cases such as nonlesional ETLE, surgical outcome predictors were hard to identify, especially in adult patients. A meta-analysis by Ansari et al found that none of the factors (age at surgery, age at seizure onset, duration of epilepsy, seizure semiology, abnormality on MRI, lateralization of seizures) were significantly associated with seizure outcome, indicating that shortening the duration of epilepsy or pursuing surgery early does not improve outcomes in this case. ${ }^{20}$

Common predictors and factors unrelated to seizure outcome in the findings of the meta-analyses for lesional and nonlesional TLE, lesional ETLE, and tuberous sclerosis complex were identified and the results are shown in Table 6. Because no predictors of seizure outcome for adult nonlesional ETLE patients were found by the meta-analysis of Ansari et al, ${ }^{20}$ common predictors could not be extracted from the findings of the reviews or meta-analysis in nonlesional ETLE.

\section{Other outcomes and interventions}

The main findings of reviews or meta-analyses on other outcomes such as discontinuation of antiepileptic drugs (AEDs) and neuropsychologic outcomes are summarized in Table 7. Further, the main findings of the meta-analyses on epilepsy surgical options or other interventions are summarized in Table 8.

\section{Discussion}

Identification of reliable prognostic factors or predictors of outcomes of epilepsy surgery is critical to reduce uncertainties for both surgical candidates and surgical teams. This study gathered together recent reviews and meta-analyses in this area, classified them into lesional or nonlesional TLE, ETLE, or tuberous sclerosis complex subgroups, summarized the findings, and made an effort to identify common predictors in order to obtain more reliable prognostic factors.

\section{Common predictors of seizure outcome}

Early research found that predictors of early recurrence include diffuse and poorly localized epilepsy, need for invasive electroencephalographic (EEG) recordings, and presence of interictal epileptiform abnormalities on postoperative EEG, ${ }^{24}$ while more recent research found that a predictor of late failure was pathology consistent with focal cortical dysplasia type $1 .{ }^{25}$ On the other hand, clinical factors, such as seizure frequency, duration of epilepsy, sex, age of onset, and laterality of seizure focus have not been shown to be risk factors for seizure recurrence. ${ }^{18,19}$ The results of this study indicate that lesional epilepsy (with a focal and identifiable lesion), an abnormal MRI, partial seizures, and complete resection are common positive predictors of seizure outcome in patients who undergo surgery for lesional or nonlesional TLE or lesional ETLE. On the other hand, indicators such as nonlesional epilepsy, a poorly defined and localized 


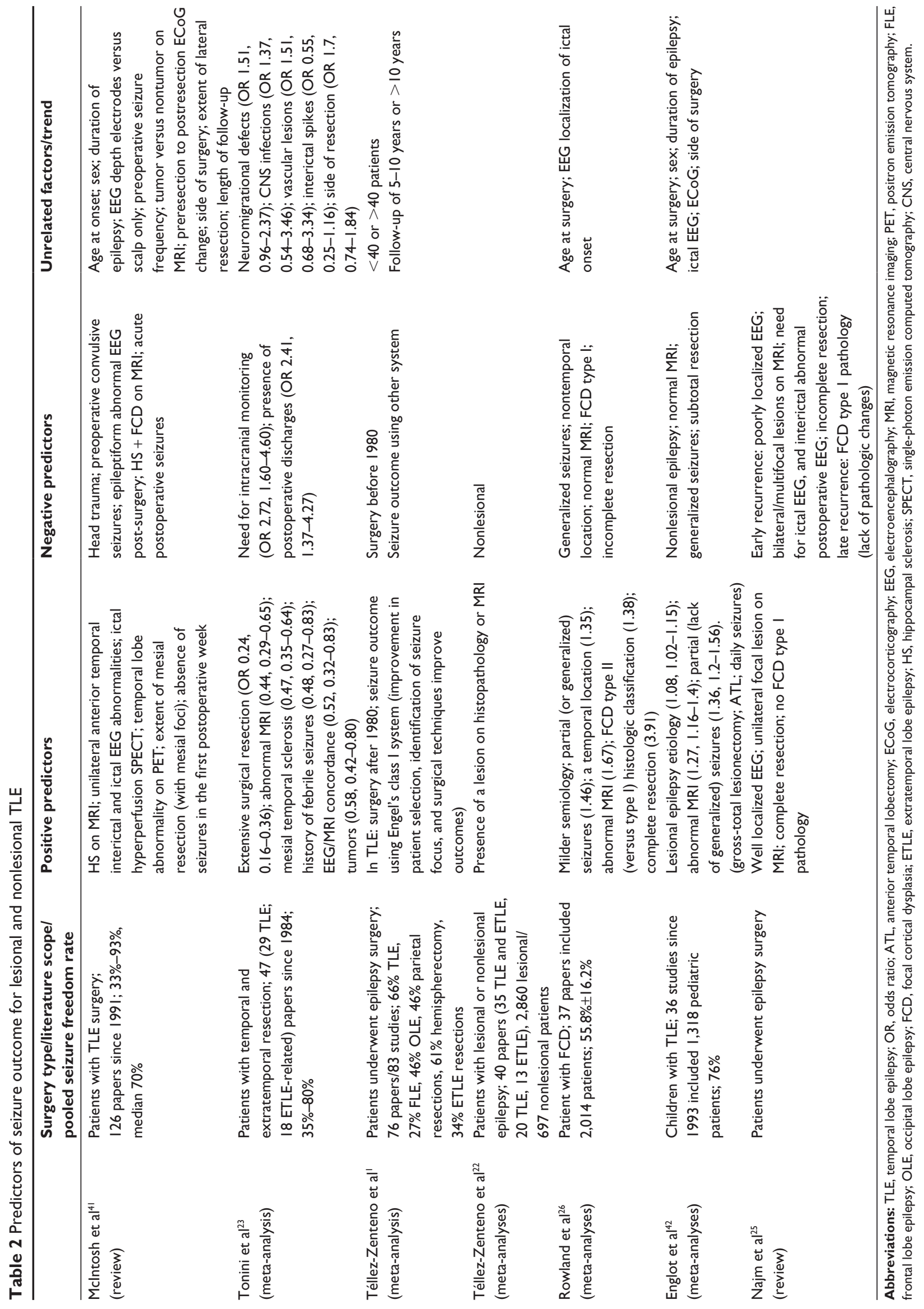




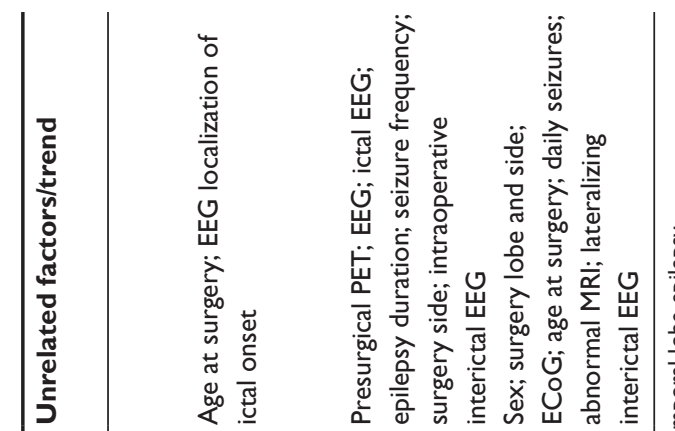

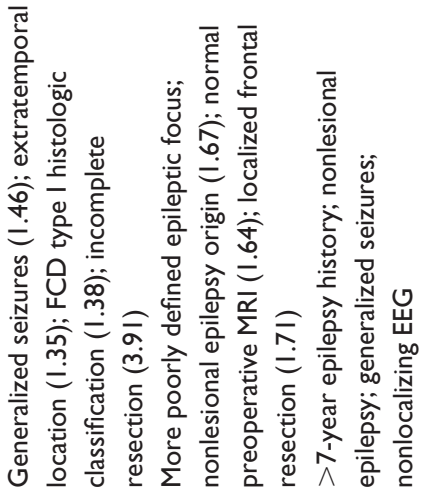

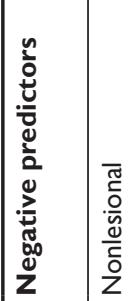

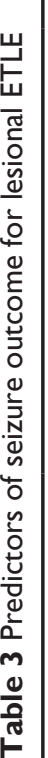
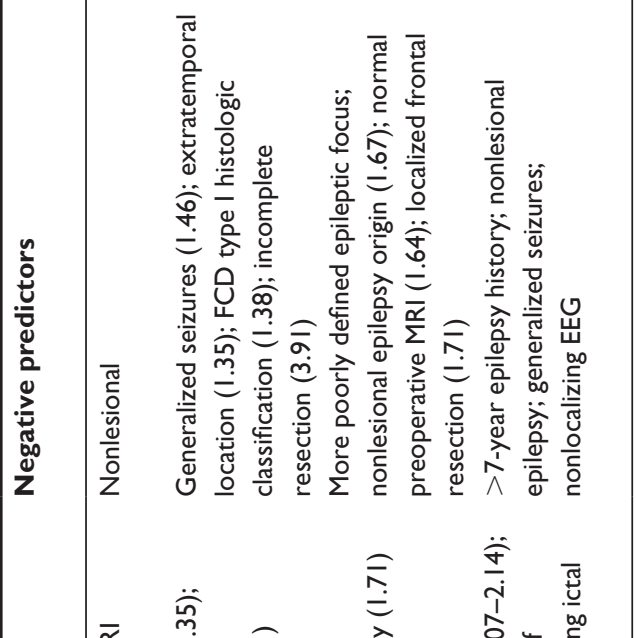

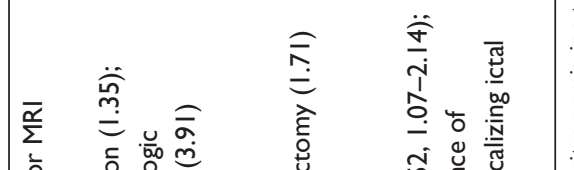

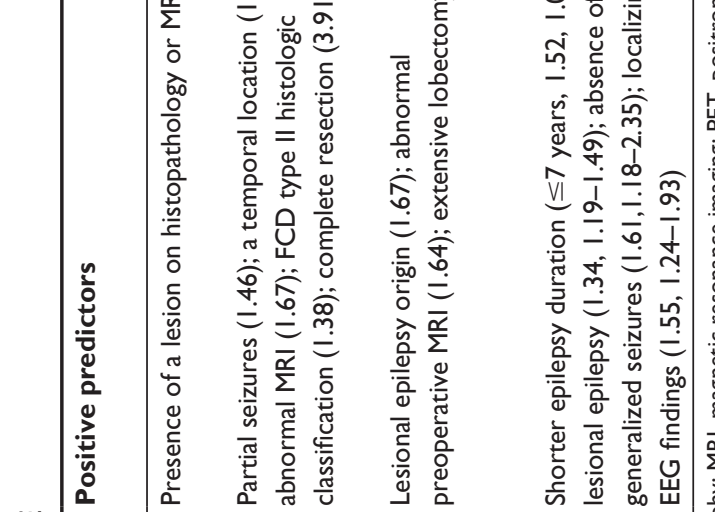

$\frac{0}{4}$

을

京

咅
ฐ

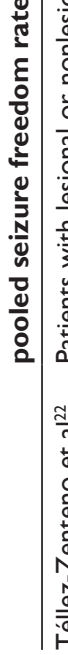

\section{$\frac{\mathscr{c}}{\mathrm{c}}$}

일

要

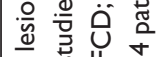

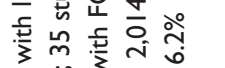

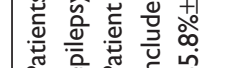

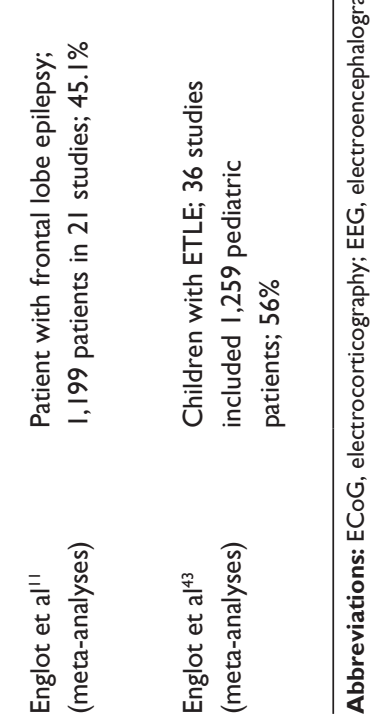

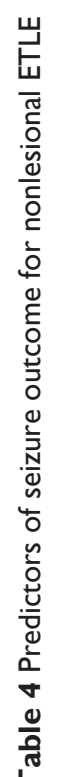

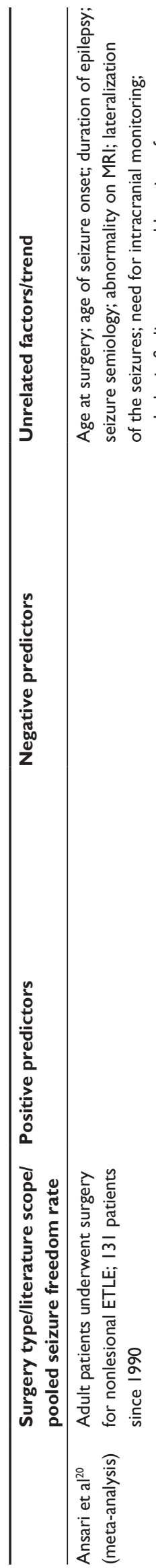

芒

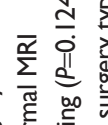

ब苍

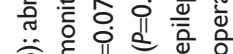

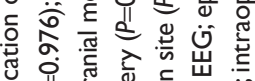

है

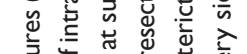

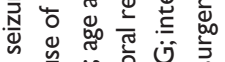

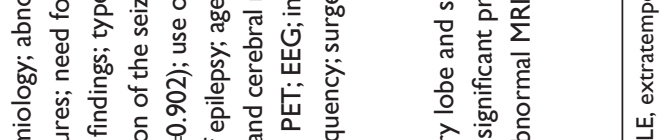

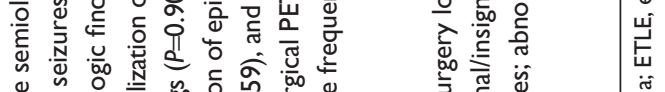

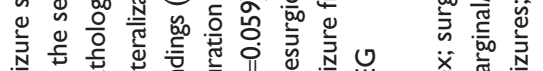

高竞
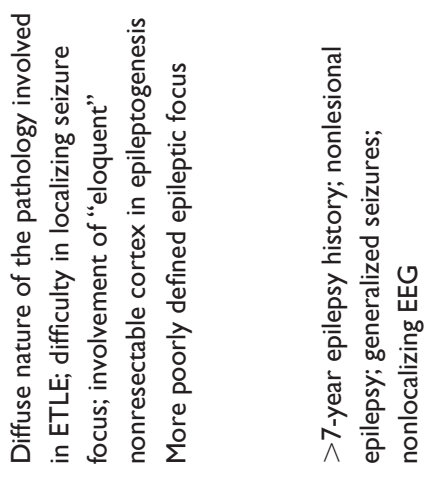

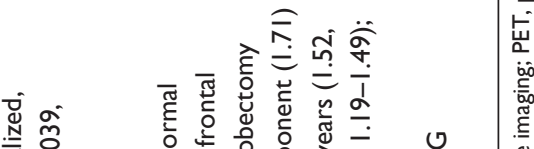

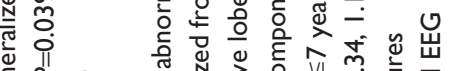

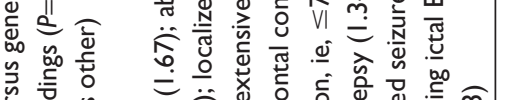

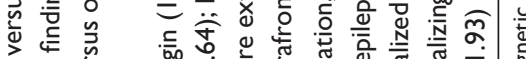

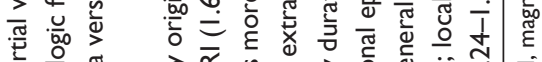

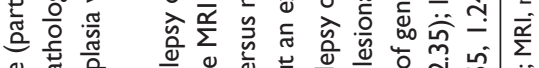

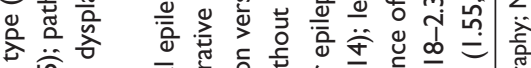

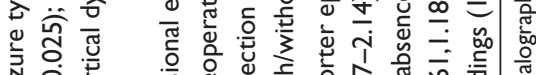

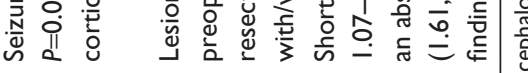

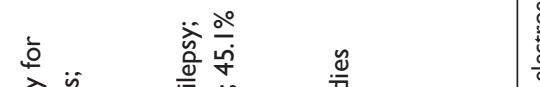

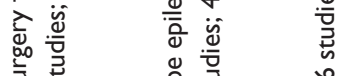

言芯造离

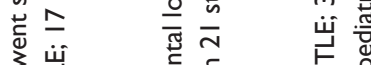

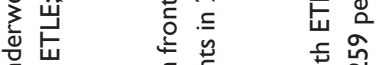

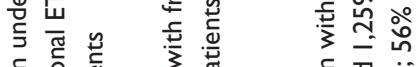

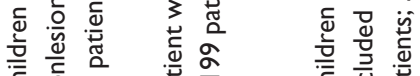

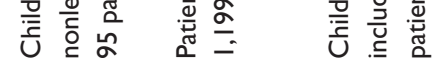

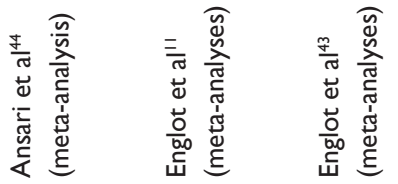

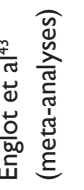




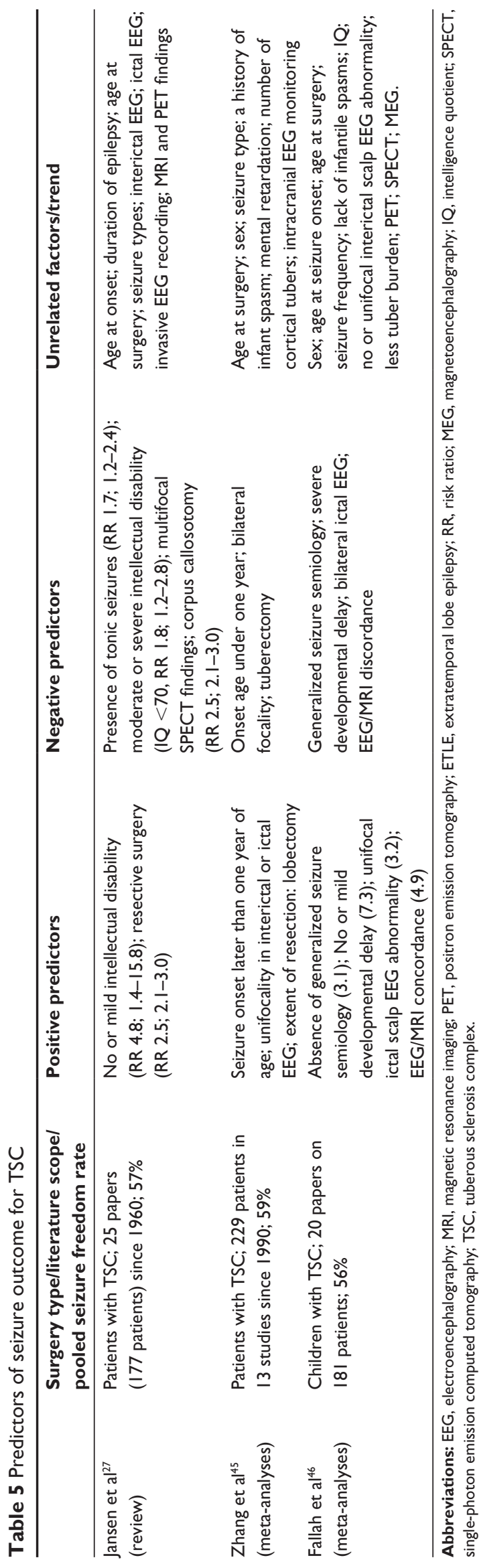

epileptic focus (with normal MRI, bilateral/multifocal lesion on MRI, or nonlocalizing EEG), generalized seizures, and incomplete resection are common negative predictors, while clinical factors such as age at surgery and side of surgery are consistently unrelated to surgical outcome following surgery for patients with TLE or lesional ETLE.

The common predictors/unrelated factors provide a very rough picture on what clinical factors are associated/ unassociated with seizure outcome and how they are related or unrelated to outcome. For example, abnormal preoperative MRI has been frequently identified as a strong positive predictor of postoperative outcome (with a wide odds ratio of 0.44-1.67), while a normal MRI and a nonlocalizing EEG have been frequently regarded as strong negative predictors, whereas duration of epilepsy and seizure frequency have been frequently identified as factors unrelated to seizure outcome. However, because no predictors were found for adult patients with nonlesional $\mathrm{ETLE}^{20}$ and there is no other meta-analysis on seizure outcome prediction in this case, common prognostic factors/predictors could not be identified for nonlesional ETLE in adults. More studies are needed to identify possible predictors/risk factors of seizure outcome in challenging cases such as nonlesional ETLE.

\section{Neuroimaging as an outcome predictor}

Mild lesions, such as mild hippocampal sclerosis and focal cortical dysplasia, are hard to identify on regular MRI. They may be missed by MRI, misinterpreted as nonlesional, and even excluded from presurgical evaluation. Therefore, there are controversies regarding the utility of neuroimaging in predicting surgical outcome. ${ }^{26}$ Given that neuroimaging modalities such as PET, SPECT, and MEG are less frequently used than MRI in presurgical evaluation, ${ }^{27}$ and usually do not reach the significance threshold in multivariate analysis as does MRI, ${ }^{11}$ they are less frequently identified as predictors of surgical outcome by meta-analyses. In addition, meta-analyses such as the one reported by Téllez-Zenteno et $\mathrm{al}^{22}$ tend to emphasize the presence of a lesion as a predictor regardless of what neuroimaging is used to identify the lesion. However, advances in neuroimaging have increased the diagnostic yield by revealing dysplastic lesions that previously eluded visual inspection, ${ }^{28}$ and the predictive value of neuroimaging with regard to outcome has been increasingly identified..$^{2-5,7-9}$ In addition to MRI, MEG/MSI, PET, and ictal SPECT also have a positive predictive value in predicting seizure outcome. ${ }^{6}$ Further, it was found that focal unilateral MRS metabolite alterations that are in agreement with the EEG 
Table 6 Common predictors of seizure outcome for lesional or nonlesional TLE, lesional ETLE, and TSC

\begin{tabular}{llll}
\hline & Lesional or nonlesional TLE & Lesional ETLE & TSC \\
\hline $\begin{array}{l}\text { Positive } \\
\text { predictors }\end{array}$ & $\begin{array}{l}\text { Lesional epilepsy; abnormal MRI; partial seizures; } \\
\text { complete resection }\end{array}$ & $\begin{array}{l}\text { Focal and identifiable lesion; } \\
\text { abnormal MRI; partial epilepsy; } \\
\text { complete resection }\end{array}$ & $\begin{array}{l}\text { No or mild developmental delay; unifocal } \\
\text { ictal EEG abnormality; extensive resection } \\
\text { (lobectomy) }\end{array}$ \\
$\begin{array}{l}\text { Negative } \\
\text { predictors }\end{array}$ & $\begin{array}{l}\text { Nonlesional epilepsy; poorly localized EEG; } \\
\text { bilateral/multifocal lesions on MRI or normal MRI; } \\
\text { generalized seizures; FCD type I; need for ictal EEG; } \\
\text { incomplete resection; abnormal postoperative EEG }\end{array}$ & $\begin{array}{l}\text { Nonlesional epilepsy; poorly } \\
\text { defined and localized epileptic } \\
\text { focus; generalized seizures }\end{array}$ & $\begin{array}{l}\text { Severe developmental delay; bilateral or } \\
\text { multifocal focality; corpus callosotomy or } \\
\text { tuberectomy }\end{array}$ \\
$\begin{array}{l}\text { Unrelated } \\
\text { factors }\end{array}$ & $\begin{array}{l}\text { Age at surgery; sex; duration of epilepsy; } \\
\text { ictal EEG; side of surgery }\end{array}$ & $\begin{array}{l}\text { Age at surgery; seizure } \\
\text { frequency; EEG; surgery side }\end{array}$ & $\begin{array}{l}\text { Age at surgery; sex; a history of infantile } \\
\text { spasm; seizure types; invasive EEG } \\
\text { recording; PET findings; tuber burden }\end{array}$
\end{tabular}

Abbreviations: EEG, electroencephalography; MRI, magnetic resonance imaging; ETLE, extratemporal lobe epilepsy; TLE, temporal lobe epilepsy; FCD, focal cortical dysplasia; TSC, tuberous sclerosis complex; PET, positron emission tomography.

focus are associated with a good outcome, while contralateral or bilateral metabolite abnormalities are associated with a poor outcome. ${ }^{29}$ Therefore, diagnostic imaging and resection have been regarded as the most important factors in prediction of seizure outcome following surgery for focal cortical dysplasia. ${ }^{26}$ The results of this study tend to support this, in that diagnostic imaging and resection were the most important factors in seizure outcome prediction, not only for focal cortical dysplasia, but also for other lesional or nonlesional TLE and ETLE. ${ }^{16,23}$

Further, the utility of neuroimaging predictors of seizure outcome has been explored. Because patients with unilateral radiographic mesial temporal sclerosis are considered "ideal" candidates for epilepsy surgery, research on outcome prediction has been done in this group of patients as a priority, and high prediction/classification accuracy has been obtained. Using a multivariable analysis model, Berg et al found that mesial temporal sclerosis (relative risk 1.47-1.49) coupled with documented etiology (1.32) and partial seizures $(1.17-1.24)$ could identify patients $(n=133$ and $n=81$, respectively) with a nearly $100 \%$ seizure-free outcome. ${ }^{30}$ Focke et al applied automatic support vector machine classification to MRI and diffusion tensor images for left or right hippocampal sclerosis in TLE, and achieved a $90 \%-100 \%$ classification accuracy. ${ }^{31}$ In addition, Feis et al found that surgical outcome could be predicted in male $(94 \%$ balanced accuracy) and female (96\% balanced accuracy) patients using presurgical structural MRI. ${ }^{21}$ These results are encouraging, but are not applicable to other cases. For example, in patients with nonlesional or bilateral/multifocal

Table 7 Main literature findings on other outcomes including discontinuation of AEDs and neuropsychologic outcomes

\begin{tabular}{|c|c|c|}
\hline & Subjects/literature scope & Main findings \\
\hline $\mathrm{Vaz}^{35}$ (meta-analysis) & Patients with RATL; I 3 studies, 324 patients & $\begin{array}{l}\text { Inconsistent results: } 14 / 22 \text { variables indicated declined nonverbal memory; } \\
8 / 22 \text { demonstrated improved nonverbal memory }\end{array}$ \\
\hline Schmidt et $\mathrm{al}^{32}$ (review) & $\begin{array}{l}\text { Patients after temporal lobe surgery; } \\
\text { I } 3 \text { retrospective and five prospective } \\
\text { studies since } 1980,1,658 \text { patients }\end{array}$ & $\begin{array}{l}\text { Rate of surgical cure: } \sim 25 \% \text { adult and } \sim 31 \% \text { children or adolescents were } \\
\text { seizure-free for } 5 \text { years without AEDs. } \\
\text { Positive predictor of surgical cure: children versus adults with HS, and } \\
\text { patients with typical versus atypical Ammon's horn sclerosis or tumor }\end{array}$ \\
\hline $\begin{array}{l}\text { Téllez-Zenteno et } \mathrm{al}^{33} \\
\text { (meta-analysis) }\end{array}$ & $\begin{array}{l}\text { Patients underwent epilepsy surgery; } \\
\text { 199I-2005; } 35 \text { papers; } 20 \% \text { of the patients } \\
\text { achieved long-term AED discontinuation }\end{array}$ & $\begin{array}{l}\text { AED discontinuation: children achieved better AED outcomes than adults; } \\
\text { longer follow-up associated with lower rates of AED discontinuation } \\
\text { Cognitive outcomes: memory decline after left temporal resections; } \\
\text { intelligence not significantly changed; long-term memory outcomes } \\
\text { associated with seizure freedom and side of temporal lobe resection; } \\
\text { negative predictors of cognitive outcome were early onset, long duration, } \\
\text { and poor seizure control. } \\
\text { Unconfirmed long-term outcomes: improved long-term psychosocial } \\
\text { outcomes reported by noncontrolled studies were less clear in controlled } \\
\text { studies }\end{array}$ \\
\hline $\begin{array}{l}\text { Ives-Deliperi and Butler }{ }^{37} \\
\text { (review) }\end{array}$ & Patient underwent ATL; 2 I papers & $\begin{array}{l}\text { Naming decline following ATL: declines in visual naming are common in } \\
\text { the dominant hemisphere; no reports of deficits in auditory naming } \\
\text { Strong predictors of naming decline: absence of structural hippocampal } \\
\text { pathology and late-onset epilepsy }\end{array}$ \\
\hline
\end{tabular}

Abbreviations: AEDs, antiepileptic drugs; ATL, anterior temporal lobectomy; RATL, right anterior temporal lobectomy; HS, hippocampal sclerosis. 
Table 8 Main literature findings on surgical options or other interventions

\begin{tabular}{|c|c|c|}
\hline & Subjects/literature scope & Main findings \\
\hline $\begin{array}{l}\text { Spencer et } \mathrm{al}^{39} \\
\text { (meta-analysis) }\end{array}$ & $\begin{array}{l}\text { Patients underwent MST } \\
\text { with/without resection; } \\
211 \text { patients at six centers }\end{array}$ & $\begin{array}{l}\text { Rates of excellent outcome ( }>95 \% \text { seizure reduction): for patients who underwent } \\
\text { MST alone, } 62 \%-63 \% \text { (partial seizure), } 71 \% \text { (generalized seizure); for patients who } \\
\text { underwent MST + cortical resection, } 68 \% \text { (partial seizure), } 87 \% \text { (generalized seizure) } \\
\text { Neurologic deficits: in } 23 \% \text { patients with MST + resection versus I } 9 \% \text { MST alone; } \\
\text { hemiparesis, memory decline, and visual field compromise (but not language and } \\
\text { sensory deficits) were found in those with MST alone } \\
\text { Insignificant predictors of outcome: EEG localization, age at epilepsy onset, duration } \\
\text { of epilepsy, and location of MST }\end{array}$ \\
\hline $\begin{array}{l}\text { Schmidt and Stavem }{ }^{38} \\
\text { (meta-analysis) }\end{array}$ & $\begin{array}{l}\text { Patients with TLE surgery } \\
\text { versus no surgery; } 29 \text { studies, } \\
\text { I,62I patients }\end{array}$ & $\begin{array}{l}\text { Rate of seizure freedom: } 44 \% \text { patients with TLE surgery versus I2\% nonoperated } \\
\text { controls } \\
\text { Pooled risk difference in favor of surgery: } 42 \% \text { ( } 95 \% \mathrm{Cl} 32 \%-5 \text { I\%) } \\
\text { Benefit of surgery: surgery + medical treatment is four times as likely as medical } \\
\text { treatment alone to achieve seizure freedom }\end{array}$ \\
\hline $\begin{array}{l}\text { Englot et a }{ }^{40} \\
\text { (meta-analysis) }\end{array}$ & $\begin{array}{l}\text { Patient underwent VNS; } \\
74 \text { studies with } 3,321 \text { patients }\end{array}$ & $\begin{array}{l}\text { Benefit of VNS: patients with generalized epilepsy and children benefited significantly } \\
\text { from VNS, seizure reduced by about } 50 \% \text { in approximately } 50 \% \text { of patients } \\
\text { Positive predictors: post-traumatic epilepsy and tuberous sclerosis; VNS predicted } \\
a \geq 50 \% \text { reduction in seizures } \\
\text { Role of VNS: an adjunctive therapy in patients not amenable to resection }\end{array}$ \\
\hline $\begin{array}{l}\text { Josephson et al }{ }^{34} \\
\text { (meta-analysis) }\end{array}$ & $\begin{array}{l}\text { Patient underwent ATL or SAH; } \\
\text { I I studies include I,203 patients }\end{array}$ & $\begin{array}{l}\text { Seizure outcome of ATL versus SAH: patients were statistically more likely to be } \\
\text { seizure-free after ATL than after SAH } \\
\text { Role of SAH: less operative risk; SAH is needed if neuropsychologic outcomes are } \\
\text { substantially different. }\end{array}$ \\
\hline
\end{tabular}

Abbreviations: $\mathrm{Cl}$, confidence interval; SAH, selective amygdalohippocampectomy; MST, multiple subpial transection; TLE, temporal lobe epilepsy; VNS, vagus nerve stimulation; ATL, anterior temporal lobectomy; EEG, electroencephalography.

TLE, because the odds ratios of the predictors (eg, abnormal MRI for focal cortical dysplasia with an odds ratio of 1.67 or probability of $0.63^{26}$ ) are relatively low, the predictive power of these common predictors is limited, and the prediction accuracy is low. Thus, the overall prediction accuracy for surgical outcome is not high, especially in challenging epilepsy cases such as nonlesional ETLE, and more research is needed to improve it.

\section{Other outcome prediction}

Discontinuation of AEDs is an important outcome of surgical treatment for epilepsy, and a surgical cure for drug-resistant epilepsy is regarded as both seizure freedom and discontinuation of AEDs. ${ }^{32}$ Téllez-Zenteno et al reported that children achieved better AED discontinuation than adults and longer follow-up was associated with less AED discontinuation. ${ }^{33}$ Schmidt et al found that better cure rates were achieved in children with hippocampal sclerosis and those with typical Ammon's horn sclerosis or tumors..$^{32}$ These findings indicate that young age is associated with a better chance of AED discontinuation.

Meta-analysis of neuropsychologic outcomes is difficult and rare due to a lack of standardized testing and reporting between studies. ${ }^{34}$ For example, Vaz found that the current research cannot provide consistent evidence regarding nonverbal memory outcome following right anterior temporal lobectomy, ${ }^{35}$ and the improved long-term psychosocial outcomes consistently reported by uncontrolled studies were less clear in controlled studies. ${ }^{33}$ However, a meta-analysis covering 35 papers (from 1991 to 2005) found that memory decline occurred in patients after left temporal resections but that intelligence was not significantly changed by surgery. ${ }^{33}$ Further, presurgical functional MRI is useful in predicting verbal memory decline following left anterior temporal lobectomy, ${ }^{36}$ but neuroimaging is not regarded as a predictor of cognitive outcomes by meta-analysis. ${ }^{33}$ Other factors seemed to be more significant. For example, long-term memory outcomes were associated with seizure freedom and side of temporal lobe resection, ${ }^{33}$ while decline in naming was associated with the absence of structural hippocampal pathology and late-onset epilepsy. ${ }^{37}$ In general, poor cognitive outcome is associated with early onset, long duration of epilepsy, and poor seizure control. ${ }^{33}$

\section{Impact of interventional options on outcomes}

Finally, treatment options and types of surgery play a critical role in determining surgical outcomes. Schmidt and Stavem reported that surgery and medical treatment is four times as likely as medical treatment alone to achieve seizure freedom. ${ }^{38}$ In epilepsy surgery, anterior temporal lobectomy is more likely to achieve seizure freedom than 
selective amygdalohippocampectomy, while selective amygdalohippocampectomy may have improved neuropsychologic outcomes. ${ }^{34}$ As adjunctive therapies, multiple subpial transection and vagus nerve stimulation could reduce (but not cure) seizures, and preserve some neuropsychologic functions. ${ }^{39,40}$

\section{Limitations}

This study is limited by the available reviews and metaanalyses identified in the literature. In addition, the simple method used in this study to identify common predictors might be biased due to the few meta-analyses available and the variable findings of the meta-analyses in each subgroup (lesional, nonlesional TLE, or ETLE). Therefore, the common predictors extracted might not reflect true outcome predictors. Ideally, a comprehensive meta-analysis could include and analyze all the related studies in the literature in each subgroup of children or adult patients, thereby providing a clearer picture of the truly reliable predictors of seizure outcome, and largely reduce the variations in the findings of different meta-analyses in each subgroup. Better methods for exploring outcome prediction and identifying reliable predictors of seizure outcome after epilepsy surgery are needed.

\section{Conclusion}

In summary, common predictors/factors for TLE, lesional ETLE, and tuberous sclerosis complex were identified in this study. Clinical factors such as lesional epilepsy, abnormal MRI, partial seizures, and complete resection are common positive predictors, and indicators such as nonlesional epilepsy, poorly defined and localized epileptic focus (with normal MRI or bilateral/multifocal lesion on MRI, or nonlocalizing EEG), generalized seizures, and incomplete resection are common negative predictors, while factors such as age at surgery and side of surgery are unrelated to seizure outcome after surgery for TLE and lesional ETLE. Diagnostic neuroimaging and resection are among the most important predictors of seizure outcome in TLE and lesional ETLE. However, no common predictors of seizure outcome were identified in nonlesional ETLE. In addition, meta-analysis of other outcomes, such as neuropsychologic outcomes, has been rare due to lack of evaluation standards. Further studies on the identification of reliable prognostic factors for surgical outcomes are needed.

\section{Acknowledgments}

This work was partially supported by the National Natural Science Foundation of China (81071211).

\section{Disclosure}

The authors report no conflicts of interest in this work.

\section{References}

1. Téllez-Zenteno JF, Dhar R, Wiebe S. Long-term seizure outcomes following epilepsy surgery: a systematic review and meta-analysis. Brain. 2005;128 Pt 5:1188-1198.

2. Lerner JT, Salamon N, Hauptman JS, et al. Assessment and surgical outcomes for mild type I and severe type II cortical dysplasia: a critical review and the UCLA experience. Epilepsia. 2009;50:1310-1335.

3. Cossu M, Lo Russo G, Francione S, et al. Epilepsy surgery in children: results and predictors of outcome on seizures. Epilepsia. 2008;49: 65-72.

4. Widdess-Walsh P, Jeha L, Nair D, Kotagal P, Bingaman W, Najm I. Subdural electrode analysis in focal cortical dysplasia: predictors of surgical outcome. Neurology. 2007;69:660-667.

5. Jeha LE, Najm I, Bingaman W, Dinner D, Widdess-Walsh P, Lüders H. Surgical outcome and prognostic factors of frontal lobe epilepsy surgery Brain. 2007;130:574-584.

6. Knowlton RC, Elgavish RA, Bartolucci A, et al. Functional imaging: II. Prediction of epilepsy surgery outcome. Ann Neurol. 2008;64:35-41.

7. Kuzniecky R, Hugg J, Hetherington H, et al. Predictive value of 1 H MRSI for outcome in temporal lobectomy. Neurology. 1999;53:694-698.

8. Eberhardt KE, Stefan H, Buchfelder M, et al. The significance of bilateral CSI changes for the postoperative outcome in temporal lobe epilepsy. J Comput Assist Tomogr. 2000;24:919-926.

9. Stefan H, Pauli E, Eberhardt KE, et al. [MRI spectroscopy, T2 relaxometry, and postoperative prognosis in cryptogenic temporal lobe epilepsy]. Nervenarzt. 2000;71:282-287. German.

10. Vale FL, Pollock G, Benbadis SR. Failed epilepsy surgery for mesial temporal lobe sclerosis: a review of the pathophysiology. Neurosurg Focus. 2012;32(3):E9.

11. Englot DJ, Wang DD, Rolston JD, Shih TT, Chang EF. Rates and predictors of long-term seizure freedom after frontal lobe epilepsy surgery: a systematic review and meta-analysis. J Neurosurg. 2012;116:1042-1048.

12. Abosch A, Bernasconi N, Boling W, et al. Factors predictive of suboptimal seizure control following selective amygdalohippocampectomy. J Neurosurg. 2002;97:1142-1151.

13. Hennessy MJ, Elwes RD, Rabe-Hesketh S, Binnie CD, Polkey CE. Prognostic factors in the surgical treatment of medically intractable epilepsy associated with mesial temporal sclerosis. Acta Neurol Scand. 2001;103:344-350.

14. Janszky J, Pannek HW, Janszky I, et al. Failed surgery for temporal lobe epilepsy: predictors of long-term seizure-free course. Epilepsy Res. 2005;64:35-44.

15. Tezer FI, Akalan N, Oguz KK, et al. Predictive factors for postoperative outcome in temporal lobe epilepsy according to two different classifications. Seizure. 2008;17:549-560.

16. Beghi E, Tonini C. Surgery for epilepsy: assessing evidence from observational studies. Epilepsy Res. 2006;70:97-102.

17. Harroud A, Bouthillier A, Weil AG, Nguyen DK. Temporal lobe epilepsy surgery failures: a review. Epilepsy Res Treat. 2012;2012:201651.

18. Kilpatrick C, Cook M, Matkovic Z, O’Brien T, Kaye A, Murphy M. Seizure frequency and duration of epilepsy are not risk factors for postoperative seizure outcome in patients with hippocampal sclerosis. Epilepsia. 1999;40:899-903.

19. Ramos E, Benbadis S, Vale FL. Failure of temporal lobe resection for epilepsy in patients with mesial temporal sclerosis: results and treatment options. J Neurosurg. 2009;110:1127-1134.

20. Ansari SF, Tubbs RS, Terry CL, Cohen-Gadol AA. Surgery for extratemporal nonlesional epilepsy in adults: an outcome meta-analysis. Acta Neurochir (Wien). 2010;152:1299-1305.

21. Feis DL, Schoene-Bake JC, Elger C, Wagner J, Tittgemeyer M, Weber B. Prediction of post-surgical seizure outcome in left mesial temporal lobe epilepsy. NeuroImage Clinical. 2013;2:903-911. 
22. Téllez-Zenteno JF, Hernández Ronquillo L, Moien-Afshari F, Wiebe S. Surgical outcomes in lesional and non-lesional epilepsy: a systematic review and meta-analysis. Epilepsy Res. 2010;89:310-318.

23. Tonini C, Beghi E, Berg AT, et al. Predictors of epilepsy surgery outcome: a meta-analysis. Epilepsy Res. 2004;62:75-87.

24. Jeha LE, Najm IM, Bingaman WE, et al. Predictors of outcome after temporal lobectomy for the treatment of intractable epilepsy. Neurology. 2006;66:1938-1940.

25. Najm I, Jehi L, Palmini A, Gonzalez-Martinez J, Paglioli E, Bingaman W. Temporal patterns and mechanisms of epilepsy surgery failure. Epilepsia. 2013;54:772-782.

26. Rowland NC, Englot DJ, Cage TA, Sughrue ME, Barbaro NM, Chang EF. A meta-analysis of predictors of seizure freedom in the surgical management of focal cortical dysplasia. J Neurosurg. 2012;116:1035-1041.

27. Jansen FE, van Huffelen AC, Algra A, van Nieuwenhuizen O. Epilepsy surgery in tuberous sclerosis: a systematic review. Epilepsia. 2007;48:1477-1484.

28. Bernasconi A, Bernasconi N, Bernhardt BC, Schrader D. Advances in MRI for 'cryptogenic' epilepsies. Nat Rev Neurol. 2011;7:99-108.

29. Hammen T, Kuzniecky R. Magnetic resonance spectroscopy in epilepsy. In: Stefan H, Theodore WH, editors. Handbook of Clinical Neurology. Epilepsy, Part I. New York, NY: Elsevier Science; 2012;107.

30. Berg AT, Walczak T, Hirsch LJ, Spencer SS. Multivariable prediction of seizure outcome one year after resective epilepsy surgery: development of a model with independent validation. Epilepsy Res. 1998;29:185-194.

31. Focke NK, Yogarajah M, Symms MR, Gruber O, Paulus W, Duncan JS. Automated MR image classification in temporal lobe epilepsy. Neuroimage. 2012;59:356-362.

32. Schmidt D, Baumgartner C, Loscher W. The chance of cure following surgery for drug-resistant temporal lobe epilepsy. What do we know and do we need to revise our expectations? Epilepsy Res. 2004;60: 187-201.

33. Téllez-Zenteno JF, Dhar R, Hernandez-Ronquillo L, Wiebe S. Longterm outcomes in epilepsy surgery: antiepileptic drugs, mortality, cognitive and psychosocial aspects. Brain. 2007;130 Pt 2:334-345.

34. Josephson CB, Dykeman J, Fiest KM, et al. Systematic review and meta-analysis of standard vs selective temporal lobe epilepsy surgery. Neurology. 2013;80:1669-1676.
35. Vaz SA. Nonverbal memory functioning following right anterior temporal lobectomy: a meta-analytic review. Seizure. 2004;13:446-452.

36. Binder JR, Sabsevitz DS, Swanson SJ, Hammeke TA, Raghavan M, Mueller WM. Use of preoperative functional MRI to predict verbal memory decline after temporal lobe epilepsy surgery. Epilepsia. 2008;49:1377-1394.

37. Ives-Deliperi VL, Butler JT. Naming outcomes of anterior temporal lobectomy in epilepsy patients: a systematic review of the literature. Epilepsy Behav. 2012;24:194-198.

38. Schmidt D, Stavem K. Long-term seizure outcome of surgery versus no surgery for drug-resistant partial epilepsy: a review of controlled studies. Epilepsia. 2009;50:1301-1309.

39. Spencer SS, Schramm J, Wyler A, et al. Multiple subpial transection for intractable partial epilepsy: an international meta-analysis. Epilepsia. 2002;43:141-145.

40. Englot DJ, Chang EF, Auguste KI. Vagus nerve stimulation for epilepsy: a meta-analysis of efficacy and predictors of response. J Neurosurg. 2011;115:1248-1255.

41. McIntosh AM, Wilson SJ, Berkovic SF. Seizure outcome after temporal lobectomy: current research practice and findings. Epilepsia. 2001;42:1288-1307.

42. Englot DJ, Rolston JD, Wang DD, Sun PP, Chang EF, Auguste KI. Seizure outcomes after temporal lobectomy in pediatric patients. J Neurosurg Pediatr. 2013;12:134-141.

43. Englot DJ, Breshears JD, Sun PP, Chang EF, Auguste KI. Seizure outcomes after resective surgery for extra-temporal lobe epilepsy in pediatric patients. J Neurosurg Pediatr. 2013;12:126-133.

44. Ansari SF, Maher CO, Tubbs RS, Terry CL, Cohen-Gadol AA. Surgery for extratemporal nonlesional epilepsy in children: a metaanalysis. Childs Nerv Syst. 2010;26:945-951.

45. Zhang $\mathrm{K}, \mathrm{Hu} \mathrm{WH}$, Zhang $\mathrm{C}$, Meng FG, Chen N, Zhang JG. Predictors of seizure freedom after surgical management of tuberous sclerosis complex: a systematic review and meta-analysis. Epilepsy Res. 2013;12:134-141.

46. Fallah A, Guyatt GH, Snead OC 3rd, et al. Predictors of seizure outcomes in children with tuberous sclerosis complex and intractable epilepsy undergoing resective epilepsy surgery: an individual participant data meta-analysis. PLoS One. 2013;8:e53565.
Neuropsychiatric Disease and Treatment

\section{Publish your work in this journal}

Neuropsychiatric Disease and Treatment is an international, peerreviewed journal of clinical therapeutics and pharmacology focusing on concise rapid reporting of clinical or pre-clinical studies on a range of neuropsychiatric and neurological disorders. This journal is indexed on PubMed Central, the 'PsycINFO' database and CAS.
Dovepress

The manuscript management system is completely online and includes a very quick and fair peer-review system, which is all easy to use. Visit $\mathrm{http}: / / \mathrm{www}$.dovepress.com/testimonials.php to read real quotes from published authors. 